\title{
EL NUEVO PANORAMA DE LOS SABERES DE LA EDUCACIÓN: DEBATES, ESTUDIOS Y PROPUESTAS
}

(1950- 1990)

Antón Costa Rico*

\begin{abstract}
RESUMEN
La construcción del conocimiento pedagógico tendrá lugar progresivamente a través de la pluridisciplinariedad y la interdisciplinariedad de las ciencias de la educación. En este escenario se rompen las pespectivas tradicionales de fuerte ascendiente filosófica, para dar paso a una elaboración realizada con el concurso de las ciencias sociales, si bien se partía de un rico legado aportado por importantes contribuciones filosóficas, psicológicas, experimentales y empíricas. El conocimiento elaborado es extraordinario y diversificado, en cuanto a los discursos y a las prácticas en distintos ámbitos de preocupación, lo que se tradujo en su especialización y en su fragmentación, al punto de hacer hoy dificil la construcción de una epistemología del discurso pedagógico, un saber fragil, complejo, en transformación y con falta de perfiles nítidos, como señaló el profesor Jaume Trilla. En estas circunstancias hemos seleccionado como lineas de fuerza aquellas que tienen que ver con el desarrollo de la educación auspiciado desde la sociología política y la sociología de la educación, o desde la teoría económica; nos hemos acercado al pragmatismo y al conductualismo; nos referimos a las propuestas anti-autoritarias; recorremos lo esencial de la psicología constructiva y cognitiva, y volvemos la mirada hacia la tesis del conocimiento como construcción social, para, finalmente, referirnos
\end{abstract}

* Profesor da Facultade de Ciencias da Educación da Universidade de Santiago de Compostela, investigador e publicista en historia da educación, con singular atención á historia da educación en Galiza.

Educ. e Filos., Uberlândia, v. 20, n. 39, p. 89-130, jan./jun. 2006. 
a las concepciones curriculares, y a la teoría y práctica docente. A su alrededor se han ido organizando los distintos campos y manifestaciones teóricas y metodológicas de las ciencias de la educación, con sus conclusiones y distintas aplicaciones.

Palabras-clave: Conocimiento pedagógico. Desarrollo social. Escuela democrática.

\begin{abstract}
The construction of pedagogical knowledge will progressively take place through the multidisciplinarity and the interdisciplinarity of the educational sciences. In this scenario, traditional views with strong philosophical ascendancy break down and develop with contributions from the social sciences, even though they had originally sprung from a rich legacy supplied by important philosophical, psychological, experimental and empirical contributions. The knowledge developed is extraordinary and varied as to the discourses and the practices in different areas of concern, which resulted in their specialization and fragmentation. These features make it difficult at present to build an epistemology of pedagogical discourse - a fragile and complex type of knowledge which is in a process of transformation and lacks clear profiles, as professor Jaume Trilla has pointed out. In these circumstances we have selected as strength lines those concerning the development of education from political sociology and educational sociology, or from economic theory; we have approached pragmatism and conductism; we refer to antiauthoritarian proposals; we go into the essential parts of constructive and cognitive psychology; and we turn our look to the thesis of knowledge as a social construction. Finally, we refer to curricular conceptions and the theory and practice of teaching. Around it the different fields and theoretical and methodological manifestations of the education sciences have been organised, together with its conclusions and different applications.
\end{abstract}

Educ. e Filos., Uberlândia, v. 20, n. 39, p. 89-130, jan./jun. 2006. 
Keywords: Pedagogical knowledge. Social development. Democratic school.

\section{La construcción del conocimiento pedagógico}

Finalizada la contienda militar y política de la II $^{\mathrm{a}}$ Guerra Mundial, las miradas se dirigieron de nuevo y con mayor fuerza hacia la educación, pues en el corazón y en la inteligencia de los hombres y de las mujeres había que construir las simientes de la paz, junto a las diversas acciones de todo tipo que pudiesen generar escenarios sociales de desarrollo y de resolución pacífica de conflictos.

Al respecto, parecía oportuno recoger un amplio legado, una rica memoria aún proyectada sobre el presente, de la que formaban parte considerables elementos teorizados, reflexionados o contrastados en las décadas y momentos precedentes, a partir de supuestos filosóficos, psicológicos, antropológicos, sociales, biológicos y culturales, que preanunciaban la transformación de la Pedagogía en Ciencias de la Educación.

Locke, Rousseau, Pestalozzi, Froebel, Herbart con su visión unitaria de la inteligencia y su preocupación por la sistematización didáctica, el humanismo pedagógico de Natorp, o el esfuerzo empírico y positivo por construir una pedagogía desde el mejor conocimiento de la naturaleza infantil. Dewey, Alfred Binet, la Escuela Nueva con sus pioneros y diversas expresiones, los estudios de Paulov y los de la Gestalt, la psicología y la educación funcional propuestas por Claparède, y también la Pedagogía Freinet como encrucijada y laboratorio para una escuela democrática, bien podrían componer una apretada síntesis de la rica memoria.

Pero el escenario ahora había cambiado aceleradamente, y había que afrontar nuevos problemas y retos, en relación con los que se hacía necesario construir un más elaborado conocimiento pedagógico. A finales del siglo XX, en efecto, podemos constatar como esto ha ocurrido.

Ante ello, ¿cómo presentar lo que podríamos considerar el 
conocimiento pedagógico construido en el contexto occidental a lo largo de la segunda mitad de dicho siglo?. Un tiempo que se inicia, finalizado el conflicto bélico, al tomar conciencia sobre la dimensión internacional y mundial de la vida de los pueblos (ONU, procesos de descolonización, extensión del constitucionalismo democrático,...) y sobre el papel a jugar por la educación y los avances científico-culturales, lo que va a suponer el nacimiento o la expansión progresiva de los sistemas escolares nacionales, así como el más logrado desarrollo de las ciencias de la educación. Un tiempo que podemos cerrar en un escenario mundial de nueva globalización, de crisis de la figura y de las promesas del keinesiano "Estado del bienestar", de multipolaridad, de tecno-cientificismo y de absoluta prevalencia del conocimiento, acompañando al ejercicio del poder.

En todo este tiempo, la concepción de la educación como intervención social en beneficio, tanto del desarrollo integral de las personas, como de las generales funciones sociales y económicas asignadas a las escuelas, llevó a incluir los programas e iniciativas educativas en todas las agendas de actuación política, aunque con distinta intensidad e implicación, según las prioridades y opciones político-ideológicas, y las capacidades de acción puestas en juego. En este marco, se fue suscitando a escala internacional y en espacios sociales crecientemente diversificados la necesidad de elaborar un nuevo conocimiento pedagógico, más complejo, y más sólido también. En torno a las múltiples dimensiones de estudio que los hechos y fenómenos educativos suscitan y que recorren toda la historia biográfica de las personas - y no sólo sus años de niñez y adolescencia-, las circunstancias de los múltiples pueblos, culturas y Estados, y que ocurren en variados contextos, y con distintos grados y modos de formalización, haciendo, así, que el estudio, la investigación y la reflexión teórica se hayan acentuado y diversificado.

Lo que antes se había apoyado en la filosofía, en la ética o aún en la psicología individual, necesitaba ahora dialogar/confrontarse con la sociología, con la antropología, con la economía, con las ciencias políticas, o con una psicología pluridisciplinaria,

Educ. e Filos., Uberlândia, v. 20, n. 39, p. 89-130, jan./jun. 2006. 
extendiendo analíticamente sus campos conceptuales y definitivos, sus preocupaciones, espacios y fronteras, más allá de las tradicionales instituciones formalizadas y "cerradas".

Y con este panorama, ¿cómo presentar, pues, una síntesis suficientemente ajustada, equilibrada y globalizadora del conocimiento pedagógico, permitiendo, sin embargo, destacar las grandes líneas de fuerza que articulan y permiten comprender el desarrollo alcanzado?. ¿Es posible, y en qué términos, categorizar el conocimiento pedagógico, en un plano sintético?. No es, en absoluto, fácil.

Con tal constancia, reduciremos la escala de observación, al centrarnos en lo que llamamos la cultura occidental; al atender, limitadamente, a problemas, procesos y situaciones que se suscitan en torno a la educabilidad (derecho individual y social) en los períodos de infancia y juventud, y al referirnos preferentemente a aquellas dinámicas organizativas socialmente más formalizadas como "aparatos escolares".

¿Qué categorías seleccionar en estos escenarios particulares indicados para presentar una síntesis deseable?. ¿Se puede, o incluso sería correcto, hablar de tendencias, o de paradigmas educativos?. ¿Hay líneas de reflexión que movilizaron intelectualmente la construcción del conocimiento pedagógico?. Jesús Palacios se preguntaba al respecto en $1996^{1}$ y concluía su dificultad.

1 PALACIOS, J., ¿Qué son las tendencias educativas en la actualidad?", Cuadernos de Pedagogía, 253(1996) p. 9. El autor había hablado y señalado distintas tendencias en La Cuestión Escolar (Laia, Barcelona, 1979), un ensayo que alcanzó una reconocida audiencia lectora al presentar sobre todo el pensamiento pedagógico entre Rousseau y Freinet, en un momento de amplio desconocimiento docente y social de estos asuntos. Presentaba, al respecto, cuatro líneas de elaboración, bajo los siguientes rótulos: "La tradición renovadora", para hablar sobre todo de la renovación escolar suscitada sobre todo por el movimiento de la Escuela Nueva, con sus apoyaturas filosóficas y psicológicas (Piaget...); "la crítica antiautoritaria" en la dirección de búsqueda de otros procesos educativos y formativos (entre Ferrer y la pedagogía institucional"; la "perspectiva política del marxismo", acogiendo desde Makarenko a las teorías de la reproducción, y "dos puntos de vista desde América Latina", para referirse a Freire y a Ilich. 
Dificultad también observable por parte de Jaume Trilla ${ }^{2}$ al establecer su propuesta binomial "pedagogías prácticas / pedagogías discursivas" y "pedagogías conservadoras/pedagogías transformadoras", configurando una vía posible de categorización que, como la de Palacios, obliga a forzar algunos encuadres. Quizás no sea tan deseable hablar de tendencias, que aluden a grados de polaridad - que, con todo, existen y pueden ser elucidadas de forma dicotómica一, como de líneas de desarrollo. Así procedió Guy Avanzini en su La pedagogía en el siglo XX en los pasados años setenta, cuando aún no se había cerrado el ciclo y con un insuficiente ejercicio. De igual modo procedió, por ejemplo, Franco Cambi en su Storia della pedagogía ${ }^{4}$ (1995), al trazar de un modo abierto un índice de dimensiones de desarrollo en el que se da cuenta del paso de la Pedagogía a las Ciencias de la Educación, de la pedagogía cognitiva (con inclusión de Piaget, Vygotsky y Bruner), de las pedagogías anti-autoritarias, de la desescolarización, de la incidencia de los mass-media, de la epistemología del discurso pedagógico y de las nuevas emergencias (feminismo, ecología e interculturalidad).

Si nos acercamos a nuestro tiempo la cuestión se complica ante el extraordinario crecimiento del conocimiento pedagógico elaborado y su diversificación en cuanto a los ámbitos y dimensiones de preocupación; también por la proliferación de los discursos, su especialización y su fragmentación, mientras se observa la disminución de autores emblemáticos con una obra original capaz

2 AYUSTE GONZÁLEZ, A., TRILLA BERNET, J., "Pedagogías de la modernidad y discursos postmodernos sobre la educación", Revista de Educación, n ${ }^{\circ} 336,2005$, pp. 219-248. Elaboran una propuesta de tendencias pedagógicas en torno a los binomios "pedagogías prácticas/pedagogías discursivas", "pedagogías conservadoras/pedagogías transformadoras", con los entrecruzamientos que entre ellas es posible establecer.

3 AVANZINI, G., La pedagogía en el siglo XX, Narcea, Madrid, 1977. Organiza el conocimiento pedagógico en torno a los siguientes apartados: Expansión de la escuela, pedagogía y ciencias humanas, educación y didáctica, el futuro de la educación, y conflictos e incertidumbres.

4 CAMBI, F., Storia della Pedagogía, Laterza, Roma, 1995.

Educ. e Filos., Uberlândia, v. 20, n. 39, p. 89-130, jan./jun. 2006. 
de marcar por ella sola una dada y sólida orientación para la práctica, reducción de discursos totalizadores sobre la escuela y la educación. La ruptura de fronteras las epistemológicas, la interdisciplinariedad en el campo de las Ciencias Sociales, y la difícil construcción de una epistemología del discurso pedagógico, relativo a un saber frágil, complejo, en transformación y con falta de perfiles nítidos, entorpecen la posible identificación de tendencias, en un tiempo además de múltiples, entrecruzados y parciales discursos.

Nosotros hemos seleccionado como líneas de reflexión, en un ejercicio atento a la diacronía del tiempo histórico, aquellas que tienen que ver con los debates y propuestas relacionadas con el conocimiento sociológico y psicológico, con la dimensión política del desarrollo educativo, con la concepción de los contenidos formativos, con la tecnología y con la función docente, fundamental en los procesos de enseñanza-aprendizaje. Reflejándolo en los siguientes índices:

- las políticas educativas a la luz de la Sociología de la Educación (1950-1972),

- el funcional-positivismo y la concepción conductista y tecnológica de la educación,

- las propuestas anti-autoritarias,

- conocimiento y aprendizaje: la Psicología constructiva y cognitiva,

- el conocimiento como construcción social y la Pedagogía Crítica,

- concepciones y prácticas curriculares,

- teoría y práctica docente.

Quizás no sea incorrecto señalar que a su alrededor se han ido suscitando y organizando los distintos campos y manifestaciones teóricas y metodológicas de las Ciencias de la Educación, con sus contribuciones y conclusiones, a las que aludiremos de un modo o de otro: la teoría de la educación, con su preocupación por la normatividad pedagógica; la filosofía de la educación con sus análisis de las propuestas derivadas de las 
diversas construcciones filosóficas; la antropología pedagógica, con sus apreciaciones éticas y morales, estéticas y culturales; la biología de la educación, atenta a los procesos de crecimiento, de maduración y de motilidad; los diversos y complejos aspectos de la psicología de la educación, aquí no examinados; las amplias pespectivas pedagógico-sociales, que se reflejan en la educación permanente y en la educación comunitaria e inclusiva, como también la amplia gama de saberes y conocimientos sociales, históricos, comparados y políticos, además de todos aquellos de más pronunciada vertiente metodológica elaborados en los campos de la didáctica y de las estrategias de aprendizaje, y de la orientación y el diagnóstico pedagógico, con sus distintas aplicaciones, según los diversos momentos y escenarios de desarrollo de las personas y de los procesos formativos.

\section{Líneas de reflexión y elaboración}

\subsection{Las politicas educativas a la luz de la sociología de la educación} (1950-1972): entre el funcionalismo y las teorías de la reproducción

La modernización estructural científico-técnica que tiene lugar a partir de los años cincuenta concederé un notable protagonismo al desarrollo educativo y a la expansión de los sistemas nacionales de educación, implicándose ahora las nuevas agencias internacionales, como la OCDE, el IIPE, el Banco Mundial o el Foro Monetario Internacional. Se imponía el tratamiento social (sociológico) de la educación y las miradas del liberalismo se dirigieron hacia la filosofía trazada por Durkheim (Éducation et Sociologie, 1922), con sus elaboraciones sobre la solidaridad orgánica, la cohesión social lograda mediante la transmisión educativa, la moral laica y racional, la profesionalización burocrática, el desarrollo de un saber profesional especializado, y la percepción de la educación como fuerza de progreso, de integración meritocrática, de control social y de legitimación del orden social.

El cuerpo conceptual e ideológico elaborado por Durkheim

Educ. e Filos., Uberlândia, v. 20, n. 39, p. 89-130, jan./jun. 2006. 
avalaba una visión intelectualista y conservadora, además de "nacional", de las instituciones escolares, haciendo de ellas, por otra parte, un aparato burocrático de dominación ideológica, como supieron ver Max Weber y Manheim, éste con su sociología del conocimiento. Esta percepción del desarrollo educativo como socialización y como instrumento de equilibrio de los sistemas sociales fue luego actualizada por Talcott Parsons (The Social System, 1951; "La clase como sistema social", 1959), quien, desde un enfoque estructural-funcionalista, contemplaba la educación como un proceso de integración social no conflictiva, lograda a través de la función social seleccionadora y meritocrática ${ }^{5}$ de los sistemas escolares, sin poner en causa las bases estructurales y los procesos de organización social.

Este enfoque se reforzó a través de la defendida conexión entre la educación y la evolución económica, que se traducía en la afirmación de la importancia de las inversiones presupuestarias en educación, como palanca de generación de capital humano (Th. W. Schultz y G. S. Becker), lo que redundaría en la aceleración del desarrollo económico. Con esta convicción la Teoría del Capital Humano inspiró, bajo el auspicio del FMI y de la OCDE, las políticas de desarrollo de los años 60 y 70 en distintos lugares del mundo, si bien diversos análisis críticos llegaron a poner de manifiesto las controversias inherentes a tales argumentos, al observar en determinados casos nacionales el contraste entre el aumento de titulaciones académicas y el declive económico, el desempleo o el aumento de las diferencias salariales, llegando a pensar que la productividad depende más de otros factores directamente económicos, y que la mayor equidad de rentas se consigue mediante la aplicación de políticas fiscales y laborales apropiadas ${ }^{6}$.

Aún bajo el peso de estas formulaciones, tanto la "rebelión" vivida en las aulas universitarias hacia el final de los años sesenta,

5 Un análisis crítico de la retórica credencialista en COLLINS, M., La sociedad credencialista, Akal, Madrid, 1989.

6 THUROW, L. C., "Educación e Igualdad Económica", en Educación y Sociedad, n 2, 1983, pp. 159-172, Akal, Madrid 
como diversos estudios sociológicos constataban que las posiciones distintas ocupadas por los estudiantes aparecían rigurosamente asociadas a la clase social de origen.

Las revisiones críticas realizadas por A. H. Halsey, J. Floud y A. Anderson en 1961, el Informe Coleman (1966: Equality of Educational Opportunity), que sugiere la conveniencia de crear programas de educación compensatoria y la organización de ciclos escolares comprehensivos, o el Informe Plowden (Inglaterra, 1967: Children and their Primary Schools) detectan que las políticas educativas de los países capitalistas no contribuían efectivamente a la movilidad social y no favorecían por ello, como sería de esperar, a la igualdad y al cambio social. Así lo pondrán de manifiesto los análisis sociológicos de Thurow (1972) y de Boudon, entre otros, produciendo una crisis de legitimidad al gran relato, incluso progresista, de la escuela "republicana".

En este contexto se comenzaron a elaborar varias corrientes de estudio y opinión crítica, de mayoritaria inspiración estructuralista y marxista, con planteamientos alternativos al funcionalismo sociológico imperante. Hoy las conocemos como las teorías sociológicas de la reproducción social y cultural. Coinciden en plantear la educación, así como las políticas educativas de los países capitalistas, como la expresión de una organización social clasista y como instrumento de reproducción de las estructuras de tal modelo de organización social, sólo formalmente democrático.

Desde una posición estructuralista y neo-marxista, podemos, así, referirnos al trabajo "Ideología y aparatos ideológicos del Estado", elaborado por L. Althusser y dado a luz en 1969, en donde denominaba al conjunto escolar público y privado como un aparato ideológico, que servía a la dominación de clase y a la reproducción social, al contribuir a garantizar las condiciones de producción.

Por su parte, R. Establet y Ch. Baudelot con su La escuela capitalista en Francia (1971) ponían de manifiesto como la escuela reproduce las relaciones de producción capitalista y sus formas de división del trabajo, distribuyendo a los alumnos en las redes Primaria/Profesional y Secundaria/Superior, yendo a ésta última aquellos alumnos en los que generalmente coincide la alta habilidad

Educ. e Filos., Uberlândia, v. 20, n. 39, p. 89-130, jan./jun. 2006. 
intelectual con un alto status social. Bowles y Gintis, desde América, mostraban conclusiones convergentes con las anteriores, en una orientación también abordada por M. Carnoy, H. Levin, R. Sharp, o M. Levitas, pudiendo hablarse, así, de la "Teoría de la correspondencia" entre los procesos estructurales y los superestructurales, si bien Carnoy y Levin introdujeron notas críticas al afirmar, por su parte, la posibilidad de las "contradicciones"7.

P. Bourdieu e J. C. Passeron, que ya en 1966 habían dado a luz Les heritiers, en La Reproducción (1970) mostraban como el origen social define las posibilidades de escolarización, y presentaban a las instituciones escolares como un aparato de dominación ideológica, en el que se ejerce violencia simbólica insensible e invisible en un mercado de bienes simbólicos, con sus mecanismos de eliminación y exclusión de todos aquellos que no posean el capital lingüístico-cultural exigible en una sociedad desigual, un código recibido por herencia y por reproducción social.

La escuela impondría una arbitrariedad cultural, mediante la inculcación de un conjunto de esquemas (arbitrarios) de pensamiento, de percepción, de apreciación y de acción, ocultando su carácter como dispositivo reproductor de las relaciones desiguales en sustitución de la coerción física, al legitimar un determinado proceso de imposición de la cultura y de la ideología dominante, con sus significados y valores, como si fuese algo natural. Es del caso señalar que esta tesis negaba la confianza en la posible autonomía del sistema educativo y conducía a un fatalismo en cuanto a la transformación de las escuelas, lo que no fue compartido posteriormente por los sociólogos definidores de una Teoría Social Crítica de la Educación, desde su teorización de

7 En el presente ensayo reducimos el aparato crítico y las referencias bibliográficas, limitándonos a menudo a señalar el autor o aquel título de obra que consideramos particularmente significativo. Con alguna frecuencia, la propia referencia bibliográfica se hace en castellano, la lengua oficial del Estado español, en la que accedimos al texto que se cita. El lector sabrá localizar oportunamente las referencias y textos precisos aquí citados. 
la resistencia, al señalar que la presencia de espacios de libertad en las instituciones educativas podía generar una lógica contradictoria con la del sistema.

Bourdieu y Paseron teorizan como sólo los alumnos que previamente poseen, por herencia familiar y social, los instrumentos precisos de "apropiación", son los únicos capaces de dominar con más provecho el capital cultural académico —un arbitrario cultural clasista-, incrementando con ello su capital. El sistema educativo reproduce de este modo la estructura del capital cultural y, a través de ello, las relaciones de clase en la sociedad, en colaboración con las demás instituciones simbólicas. Esta posición sociológica, más compleja, condujo a cambiar la imagen de las instituciones escolares, alejándola de los modelos más simplistas y mecanicistas.

En esta misma perspectiva hay que situar el enfoque etnometodológico y los análisis del inglés Basil Bernstein, quien puso de relieve el papel de la educación al servicio de la reproducción cultural con su Teoría de los Códigos Lingüísticos (restringido y elaborado) y sus análisis sobre el poder, los procesos de transmisión y el control social; sobre las reglas jerárquicas del discurso y sobre la práctica pedagógica. Según Bernstein la escuela selecciona al alumnado a través del lenguaje; el que allí se utiliza hace relación a un código elaborado que no dominan o ante el que tienen serias dificultades los niños de los sectores sociales más desfavorecidos. Con todo, L. Lavob hacia los últimos años setenta se distanciaba de Bernstein al argumentar con datos contrastados que las diferencias lingüísticas no afectarían tan negativamente como Bernstein sostenía.

Los posteriores desarrollos y revisiones (M. Cherkaoui, B. Charlot, J. Lautrey, Ph. Perrenoud), las reflexiones de la teoría crítica y los estudios sobre el currículum, la administración escolar y el profesorado que en las mismas décadas se abrieron paso, guardan del mismo modo una muy importante interrelación con las anteriores posiciones y análisis críticos.

Educ. e Filos., Uberlândia, v. 20, n. 39, p. 89-130, jan./jun. 2006. 


\subsection{EL funcional-positivismo y la concepción conductista y tecnología de la educación}

Bajo la influencia de Paulov y de Watson se desenvolvió a partir de los años 30 el conductismo, como corriente de estudio del comportamiento humano observable, bajo el supuesto de la inaccesibilidad al interior del cerebro, concebido como una especie de caja negra, propugnando, pues, el objetivismo como método de estudio, mientras se tendía a negar todo aquello no empíricamente observable y cuantificable, como los conceptos de naturaleza humana, conciencia y personalidad.

En esta perspectiva hay que situar al psicólogo de la Universidad de Harvard F. Skinner, que llevó a cabo distintas investigaciones sobre el condicionamiento del aprendizaje en contextos escolares, publicando sus primeros resultados concluyentes en el año 1953 en Sciencie and Human Behavior, con la conclusión de que el comportamiento humano podía ser explicado por los principios del condicionamiento operante.

Según esta teoría, el aprendizaje se presenta como la asociación de un acto específico o de una operación a una recompensa $(\mathrm{O} \rightarrow \mathrm{R})$. Esto es, inmediatamente de una determinada reacción a un estímulo, se debe ofrecer un estímulo de refuerzo positivo o negativo, con lo que se aumentaría la probabilidad de que tengan lugar o se eviten otras posibles reacciones no deseadas. Los estímulos discriminatorios ofrecidos, modelan la conducta deseada, por estar asociados a consecuencias agradables y por conducir a un aumento de la frecuencia de las respuestas deseadas, procurándose en esto la evitación del error, porque no permitiría una correcta continuación en el aprendizaje posterior. Estas eran las tesis expresadas por Skinner en su The technology of teaching, en 1968. Así, en el condicionamiento operante skinneriano se identifica aquello que se desea fortalecer, se recompensa a alguien cada vez que exhibe una conducta deseada y se recompensa también la expresión de las actitudes previstas.

Su aplicación en el campo educativo debería propiciar la 
adquisición de competencias intelectuales y de conocimientos, mediante la puesta en práctica de procesos de enseñanzaaprendizaje guiados por objetivos formulados en términos concretos de comportamiento esperable, enunciando actividades observables y medibles de los alumnos. Su operativización tiene lugar con la ayuda de materiales curriculares de enseñanza programada, delimitados y secuenciados (de lo concreto a lo general), y mediante la realización de una actividad procesual rigurosamente planificada y evaluada, con la introducción de constantes medidas de feed-back y de refuerzo, de tal modo que a medida que el aprendizaje acontece, los alumnos puedan mejorar su autoestima, aumentar sus expectativas educativas y ganar en autonomía. Se ha escrito que esta perspectiva del aprendizaje supone destinar una mayor atención a la transmisión de conocimientos que a los procesos cognitivos posibles y activados, requiriendo de los profesores un notable dominio de destrezas a favor de la programación didáctica.

Inspirándose en la teoría skinneriana y en las propuestas conductistas de R. Tyler (1949), el creador del movimiento de los objetivos de aprendizaje, B. S. Bloom, profesor de la Universidad de Chicago, creó un modelo de enseñanza para la Maestría (Mastery Learning), basado esencialmente en la certeza de que con procesos adecuados de enseñanza individualizada, el 95\% de los alumnos puede alcanzar el "dominio" de las capacidades y conocimientos fundamentales, sirviéndose para esto de una "taxonomía de objetivos cognitivos" (1956), que particulariza en cada materia las operaciones cognitivas básicas sobre las que se organizan jerárquicamente las demás operaciones, de acuerdo con la complejidad creciente de los procesos cognitivos, para poder dar cumplimiento a una amplia taxonomía de objetivos generales, específicos y comportamentales, evaluados todos en su consecución. De este modo, los profesores tendrían a su disposición una estrategia para la organización sistemática de los procesos y momentos de aprendizaje, con márgenes para alguna creatividad y capacidad dinámica personal.

Educ. e Filos., Uberlândia, v. 20, n. 39, p. 89-130, jan./jun. 2006 
Un modelo eficientista y tecnicista, y un sistema pedagógico controlado en cuanto al recorrido a realizar para alcanzar el saber, que conectaba con el funcionalismo sociológico y económico, por su asentamiento en el paradigma de la gestión empresarial, que conducía a la apreciación del conocimiento de acuerdo con su valor en el mercado.

R. Gagné en 1970 al dar a luz su teoría del aprendizaje partió asimismo de principios conductistas, aunque incorporó elementos propios de las teorías cognitivas e integró las teorías de procesamiento de la información como esquema explicativo de las condiciones internas del aprendizaje, pasando a entender el refuerzo como motivación intrínseca, a diferencia de Skinner. Aún así, Gagné presenta el diseño de instrucción como un modelo sistémico y estático, en definitiva, también esquematizador. Entiende Gagné que lo que se aprende puede ser jerarquizado, formando conjuntos de informaciones significativos y estructurados, a través de procesos de aprendizaje resueltos en ocho fases, desde la creación de la motivación hasta la fase de perfomance y de feed-back, siendo una función primordial de los profesores crear situaciones de aprendizaje y estimulaciones externas que influencien favorablemente a dicho aprendizaje.

En el conjunto de esta orientación la Didáctica se identifica con la Tecnología; es decir, con una forma precisa de programación y de evaluación que ofrece la "garantía" de la precisión y la claridad tecnológica y la "seguridad" de la eficacia y la eficiencia, sin cuestionamientos epistemológicos ni ideológicos, en conexión con el Management Sciencie Movement.

Como sabemos, la propuesta ha alcanzado notable éxito y utilización, pero también críticas, por su no consideración de la importancia que en el aprendizaje tienen el razonamiento, el lenguaje y las emociones; por penalizar el pensamiento divergente; por establecer una neta separación entre la elaboración y la ejecución. Al hacer predominar una visión mecánica del mundo y al reducir todo a lo fáctico "se niega valor a otras dimensiones, como los aspectos intuitivos, imaginativos, creativos y éticos de la conciencia y de la naturaleza humana, tan presentes en los procesos 
de aprendizaje $\mathrm{e}^{\prime \prime}$, quedando la racionalidad reducida a operaciones de cálculo para el éxito utilitarista, sin entrar en otras consideraciones relacionadas con los procesos de asimilación y de construcción del pensamiento, como indica Álvarez Méndez, o con las funciones y finalidades del conocimiento.

\subsection{Las orientaciones antiautoritarias}

Los estudios de la conducta humana en relación con la educación y el aprendizaje se vieron así mismo influidos por el desarrollo del Psicoanálisis con su estudio de la psicología profunda y la demostración por parte de Freud del poder emocional del subconsciente. La continuación de esta investigación por parte de su hija Anna Freud, de Hanz Zulliger (La psychanalyse a l'école, 1930) y de Melanie Klein, quien aplicó las teorías freudianas al psicoanálisis infantil, permitió proyectar el psicoanálisis en el campo educativo, al contribuir al mejor conocimiento de las pulsiones más profundas en la infancia y a modificar mismo su concepción.

Estas preocupaciones estuvieron presentes en las conocidas comunidades escolares de Hamburgo (1919-1935) y en las reflexiones de W. Reich y de J. R. Schmidt. Y guiaron la acción antiautoritaria de Alexander S. Neill (1883-1973) en la singular escuela inglesa de Summerhill, caracterizada por su régimen de autogobierno, por la plena confianza en la bondad del ser humano y el respeto al principio del placer, con la intención de formar personas felices y equilibradas.

Una perspectiva paralela fue desarrollada por C. Rogers con su propuesta de no-directividad, que implicaba la defensa de una actitud razonada de limitación del poder del maestro/director, como forma de ayudar a los alumnos y de aproximarse al efecto formador de la educación, al confiar en la potencialidad natural

8 ÁLVAREZ MÉNDEZ, J. M., Entender la Didáctica, entender el Currículum, Miño y Dávila, Madrid, 2001, p. 195.

Educ. e Filos., Uberlândia, v. 20, n. 39, p. 89-130, jan./jun. 2006. 
del ser humano para aprender y desarrollarse, singularmente en su dimensión emocional como indicó en Libertad y creatividad en la educación. Reclamando la no-directividad, también M. Lobrot con su Pédagogie Institutionnelle (1966) puso de relieve cómo las informaciones matizadas afectivamente o los sentimientos cognitivamente orientados deberían ser considerados, tanto en la formación del pensamiento como en el desarrollo de la conducta, reclamando por ello la autogestión pedagógica y el derecho a tomar la palabra por parte de los alumnos.

En este contexto de preocupaciones, los impulsos a la autogestión, la contestación juvenil y las perspectivas y demandas antiautoritarias escolares, se vieron fortalecidas con las aportaciones teóricas de M. Foucault (Surveiller et punir), de M. Postic (La relation educative, 1982) y de G. Mendel y Ch. Vogt, con sus propuestas socio-analíticas trazadas en El manifiesto de la educación y en La descolonización del niño, obras éstas también elaboradas en los pasados años setenta.

Hablamos de unas reflexiones también presentes, con acentos singulares, en la orientación conocida como "pedagogía institucional", inicialmente elaborada por F. Deligny en París en 1950, y que continuaron en los sesenta F. Oury, A. Vasquez, R. Fonvielle, o G. Lapassade, autores estos en parte desgajados de la Pedagogía Freinet, y que concedieron atención a las aportaciones psicoanalíticas, al tiempo que cuestionaban el directivismo adulto en las instituciones escolares: la profundización de la clase cooperativa desde la óptica de la autogestión pedagógica, la preocupación por la dinámica de los grupos (Kurt Lewin) y por la resolución de los conflictos, así como la realización de actividades instituyentes de los grupos, marcaron la línea de trabajo pedagógica desarrollada vigorosamente durante los pasados años setenta.

2.4. Conocimiento y aprendizaje: Psicología constructivista y cognitiva

En el contexto pedagógico ginebrino en el que desarrollaban sus actividades Ferrière, Claparède y Bovet, la figura del psicólogo 
Jean Piaget (1896-1980) comenzó a destacar desde el inicio de los años 30 con sus primeras publicaciones relativas a una teoría bastante compleja, pero científicamente fundada y con raíces en el evolucionismo y en la Gestalt ${ }^{9}$, acerca del desarrollo psicológico y la formación de los conocimientos, conocida como "epistemología genética": esto es, el estudio de la formación del conocimiento (en particular de carácter científico) según la historia, la sociogénesis, y sobre todo, los orígenes psicológicos de las nociones y operaciones sobre las que se basa o construye, con el objetivo de describir y explicar las leyes generales de desarrollo de las estructuras cognitivas ${ }^{10}$.

Siguiendo un método experimental propio Piaget investigó el desarrollo intelectual infantil, sentando la tesis de que la inteligencia es un proceso y no un estado y la de que los niños desarrollan estructuras de conocimiento y aprendizaje, por medio de construcciones sucesivas de creciente complejidad e integración, a partir de sus propias experiencias y como sujetos activos en su propio proceso de evolución; todo ello mediante adaptaciones (dialécticas) sucesivas enmarcadas en dos mecanismos indisociables: el de la "asimilación" de datos de la experiencia, y el de la "acomodación" a las circunstancias cambiantes de la realidad, para buscar el "equilibrio" del individuo, siendo este equilibrio o reestructuración de los esquemas o sistemas cognitivos propios (asimilar y reestructurar) la condición del aprendizaje. Dicho de otro modo: el desarrollo intelectual, según la teoría piagetiana, evolucionaría mediante un proceso continuo de sucesivas equilibraciones de las estructuras cognitivas. Por esta vía, los conocimientos tienden a ser integrados en estructuras estables, gracias a los estados de equilibrio, para Piaget fuertemente anclados en la base biológica humana, lo

9 El constructivismo piagetiano tiene sus raíces en la Gestalt que siempre rechazó el conductismo por mecanicista, y sostuvo que el aprendizaje de los organismos superiores se produce por insigth, por comprensión inmediata e intuitiva, súbita o discontinua, pero no por ensayo y error.

${ }^{10}$ Piaget expuso el conjunto de su elaboración en diversas obras; singularmente: Psicología y Pedagogía, Ariel, Barcelona, 1969; El nacimiento de la inteligencia, Aguilar, Madrid, 1969 (orig: 1936); La equilibración de las estructuras cognitivas, Siglo XXI, Madrid.

Educ. e Filos., Uberlândia, v. 20, n. 39, p. 89-130, jan./jun. 2006. 
que convertiría al desarrollo psicológico en un proceso inevitable, más allá de la intervención o no de los factores sociales. Lo que ha llevado a hablar de su excesivo "optimismo biológico".

Piaget entendía también que los mecanismos de asimilación y de acomodación se operacionalizan a través de distintas fases evolutivas de la inteligencia infantil, tres o cuatro grandes estadios o cambios discontinuos que conceptuó como los de la inteligencia sensorio-motriz, enriquecida con la fase de la representación o preoperatoria, el de la inteligencia operatoria concreta, y el de la inteligencia operatoria formal, o inteligencia abstracta.

Con el progresivo aumento y maduración del desarrollo cognitivo aumenta paulatinamente la capacidad cognitiva y sus representaciones mentales, que son las que orientan la acción y el comportamiento del individuo, debiéndose tener en cuenta en todo esto la interacción de factores internos (biológicos y neurológicos) con otros externos, como la interacción social y las experiencias afectivas.

A pesar de su riqueza conceptual y de las aportaciones que Piaget formula, no se trata de una teoría pedagógica, siendo bastante difícil operacionalizar sus tesis centradas en el "sujeto epistémico", aunque las operaciones mentales que él descubre o establece facilitan la puesta en marcha de dispositivos didácticos; un asunto sobre el que el mismo Piaget, de todos modos, reflexionó en distintas obras ${ }^{11}, \mathrm{y}$ así también otros autores ${ }^{12}$ : Piaget enfatizó

${ }^{11}$ PIAGET, J., Psicología y Pedagogía, Ariel, Barcelona, 1969; A donde va la educación, Teide, Barcelona, 1974; Seis estudios de psicología, Seix Barral, Barcelona, 1976; o Psicología del niño (en colaboración con B. Inhelder), Morata, Madrid, 1969.

${ }^{12}$ Entre otros: AEBLI, H., Una didáctica fundada en la psicología de J. Piaget, Kapelusz, Buenos Aires, 1958; COLL, C., Psicología genética y educación, Oikos-Tau, Barcelona, 1981; DELVAL, J., Crecer y pensar, Paidós, Barcelona, 1991; FURTH, H., Las ideas de Piaget: su aplicación en el aula, Kapelusz, Buenos Aires, 1971; FURTH, H. \& WACHS, H., La teoría de Piaget en la práctica, Kapelusz, Buenos Aires, 1978; KAMII, C. (en colab.), El niño reinventa la aritmética: implicaciones de la teoría de Piaget, Visor, Madrid, 1983; KAMII, C. \& DEVRIES, R., Juegos colectivos. Implicaciones de la teoría de Piaget, Visor, Madrid, 1988; KAMII, C., DEVRIES, R., La teoría de Piaget y la educación preescolar, Visor, Madrid, 1985; MORENO, M., SASTRE, G., Descubrimiento y construcción de conocimientos, Gedisa, Barcelona, 1980.

Educ. e Filos., Uberlândia, v. 20, n. 39, p. 89-130, jan./jun. 2006. 
el aprendizaje y la actividad de los alumnos como una cuestión pedagógica central, al ser el conocimiento el resultado de un proceso de construcción por interacción entre el sujeto y los objetos con los que se confrontan; una actividad, que no ha de entenderse necesariamente como manipulación física, sino también como actividad reflexiva, intelectual y verbal (algo distinto del activismo y del empirismo irreflexivo), con una finalidad constructiva.

De lo cual, se desprende, según Piaget, que es necesario hacer actuar a los niños, para que descubran a través de la experiencia, lo que se les quiere enseñar, y llevarles a adquirir una conciencia correcta de los resultados de su acción, lo cual es más difícil, y supone un progresivo dominio verbal.

Son múltiples las implicaciones educativas y de metodología didáctica que de lo dicho se desprenden, y en tal sentido desde los pasados años sesenta se llevaron a cabo múltiples y no siempre adecuadas traducciones a la acción, a través de experiencias que en algunos casos han servido también para comprender la importancia de los conflictos cognitivos, sobre lo que había trabajado G. Bachelard, o el papel del error en la construcción de los aprendizajes, cuestiones éstas sobre las que se detuvieron, como veremos, J. Bruner y D. Ausubel, entre otros.

En este sentido, la producción pedagógica y didáctica inspirada en la Psicología Genética es basta y diversificada, enmarcándose en lo que ya es común denominar como concepción constructivista de la enseñanza y del aprendizaje, un amplio enfoque en el que convergen diversas teorías psicológicas y educativas.

Hoy ligamos a la perspectiva piagetiana el concepto de aprendizaje significativo, las propuestas de la Didáctica operatoria, las tesis que hablan de las conexiones entre el aprendizaje y el desarrollo, la distinción de categorías diferenciales pero no disociadas de conocimiento (físico, lógico-matemático, social), la importancia del enfoque didáctico por problemas e interdisciplinar (contradictorio con la fragmentación disciplinaria), o la defensa de una formación teórico-práctica .

Siguiendo sus pasos, o en relación de proximidad con esta psicología genética, habría que citar, al fin, los trabajos de R. Zazzo,

Educ. e Filos., Uberlândia, v. 20, n. 39, p. 89-130, jan./jun. 2006. 
Ajuriaguerra, Stambac, Perron, Anzias, y los de Henri Wallon, quien con sus obras Evolución psicológica del niño (1941) y Los orígenes del pensamiento en el niño (1945) trató de aprehender al niño en su totalidad y en la diversidad de sus condiciones sociales de existencia, esforzándose, en particular, en identificar los fundamentos psicobiológicos de la afectividad y los determinismos psicosociales de las manifestaciones afectivas, viendo el papel de las emociones en la vida intelectual.

El refuerzo de la dimensión social, según la filosofía del materialismo dialéctico, aproximaba a Wallon a los planteamientos de L. S. Vigotsky (1896-1934), quien, como Piaget también se interesó por el proceso de evolución psicológica de los seres humanos en tanto que especie y por el de cada individuo (desarrollo autogenético) en particular, en una perspectiva distinta de las teorías conductistas que habían abandonado el estudio del pensamiento y del lenguaje, en tanto que actividades psíquicas complejas y de muy difícil abordaje experimental.

Vigotsky, acogiéndose igualmente a la perspectiva de la Gestalt y profundizándola desde el materialismo histórico y dialéctico, entiende los fenómenos psíquicos como proceso, en movimiento y con una historia, que se operacionalizan dialécticamente, en relación con la sociedad y la cultura.

Sobre estos supuestos, considera que el desarrollo mental no es, como sostenía Piaget, un proceso inevitable, y que, por el contrario, se produce con ayuda de instrumentos mediadores de carácter cultural como es el lenguaje, y de ahí la importancia de las intervenciones educativas. Desarrollo mental y conciencia se forman, pues, de modo activo a través de un proceso intersociológico y social (socio-histórico y cultural) con la mediación del lenguaje, lo que hace que el aprendizaje en interacción con otros, con la ayuda de los adultos, contribuya de modo relevante al desarrollo, como expuso en su obra de 1929 Pensamiento y Lenguaje, en donde describía el proceso de interiorización del lenguaje, como principal instrumento de la conciencia humana.

En esta orientación, elaboró Vigotsky la noción de "zona o zonas de desarrollo próximo" y potencial (establecida por A. 
Leontiev y A. Luria), como la distancia a cubrir entre el nivel de desarrollo intelectual actual de un alumno y el nivel de desarrollo exigido para la resolución autónoma de un nuevo problema, lo que se podría solucionar a través de procesos de aprendizaje significativos, determinados por la resolución de problemas, posibilitando, de este modo, enfocar la enseñanza como la facilitación de las condiciones que preceden y hacen posible la consecución del nivel madurativo siguiente. Desde este punto de vista, los alumnos con más oportunidades de aprender podrían alcanzar un mejor desarrollo cognitivo, de donde deriva la importancia de las políticas democráticas de educación.

Desde el conocimiento de los conceptos y posiciones tanto de Piaget como de Vigotsky, Jerome S. Bruner (1915), el fundador y director del "Center for Cognitive Studies" de Harvard (1960), elaboró (The relevance of education, 1962) una concepción de "aprendizaje por descubrimiento": un proceso globalizador de adquisición y de construcción de significados por descubrimiento progresivo de conceptos, lo que hace preciso conocer el funcionamiento mental del niño", atribuyendo una gran importancia a la actividad directa de los estudiantes sobre la realidad, a condición de ser percibida como problema a resolver, esto es, de modo hipotético y heurístico, pudiéndose hablar, según Bruner, de tres modelos progresivos de aprendizaje en relación con tres estadios: el activo, el icónico y el simbólico.

Además, Bruner concede un papel muy relevante a la cultura, al lenguaje y a los modos de representación, reconociendo también un importante papel a la ciencia, no tanto a los hechos, fenómenos y teorías, cuanto a los procesos de descubrimiento científico y a las metodologías de análisis.

Todo ello dentro de un concepto de aprendizaje en espiral, de donde dimana la propuesta de organización de los currículos y de las prácticas de enseñanza, alrededor del proceso de reconstrucción de los saberes científicos, mediante la interiorización de sus principios, aprendiendo de la propia práctica.

Las posiciones de Bruner influyeron en los estudios y programas de desarrollo curricular, aunque la generalización abusiva de sus

Educ. e Filos., Uberlândia, v. 20, n. 39, p. 89-130, jan./jun. 2006. 
tesis hizo que muchos profesores se sintiesen presionados para privilegiar el uso sistemático de procesos de investigación y la metodología de descubrimiento, en perjuicio de un mayor equilibrio y diversificación metodológica, dado que también se aprende mediante la recepción de información con metodologías expositivas. A este respecto, Ausubel, en 1978, llamó la atención sobre las limitaciones del modelo de Bruner en cuanto al aprendizaje de las ciencias; el aprendizaje por descubrimiento —indica- es bueno para los primeros años de la escolaridad, pero es deficiente para el dominio de principios y de leyes científicas.

David Ausubel, que recoge muchos de los planteamientos de Piaget y de Bruner, profundizó en el estudio de las condiciones de producción del aprendizaje cognitivo, bajo la influencia complementaria de las teorías de procesamiento de la información (sistemas de memoria, procesos de codificación) elaboradas en los últimos años 50, presentando sus posiciones en la obra Educational Psychology en 1968, construyendo la doble teoría del aprendizaje verbal significativo, y del proceso de instrucción o de los organizadores previos, una teorización que interrelaciona la estructura cognitiva con la estructura lógica de quien aprende, examinando pues los factores contribuyentes a un aprendizaje significativo.

Hablamos de un aprendizaje significativo porque puede relacionarse de un modo consistente y no arbitrario con las estructuras cognitivas del sujeto, respondiendo a sus interrogaciones, necesidades e intereses, por lo que puede percibir un valor funcional en sus contenidos.

Para que se produzca tal aprendizaje el contenido que el alumno va a aprender ha de ser potencialmente significativo (lógica y psicológicamente), es decir, ser susceptible de dar lugar a la construcción de significados, produciéndose una transformación. Los significados construidos son, pues, resultado de una compleja serie de interacciones (alumno, contenidos, profesor), siendo el docente guía en este proceso de construcción del conocimiento, por medio de tareas y actividades didácticas, sabiendo, por otra parte, que dicho proceso es social y no sólo cognitivo.

Educ. e Filos., Uberlândia, v. 20, n. 39, p. 89-130, jan./jun. 2006. 
Ausubel enfrentó los problemas que presentaba aprender en el aula. Las propuestas conductistas a este respecto de planificación curricular eran escasas y favorecían un aprendizaje repetitivo, pero dificultaban el desarrollo de un aprendizaje significativo de conceptos relevantes. Tampoco Piaget ni Gagné, desde presupuestos no coincidentes, habían elaborado teorías generales de aprendizaje.

La teoría del Aprendizaje Significativo, que sitúa la construcción de significados como elemento central del proceso de enseñanza/aprendizaje, y que se integra dentro de un modelo constructivista de interpretación del desarrollo cognitivo, permite, en cambio, profundizar en los mecanismos de aprendizaje: nos describe como aprende el individuo y sirve de guía, tanto para el diseño del currículo, como para la práctica educativa del aula y para la evaluación.

En este sentido, propone Ausubel ordenar el proceso instructivo según la organización cognitiva del alumno, y no según las disciplinas, partiendo de que los conceptos nuevos deben ser adquiridos, no a través de la vía mecanicista com o indicaba la pedagogía por objetivos, sino partiendo de los conceptos relevantes existentes en la estructura cognitiva del aprendiz, y de ahí el papel de los organizadores previos.

A pesar de que no todo se aprende así; de que, por el contrario, hay alumnos que aprenden mejor en ambientes directivos y estructurados y de que hay asuntos que pueden ser mejor enseñados con metodologías expositivas y demostrativas, las orientaciones y tesis de Ausubel gozan de un notable impacto académico y escolar.

Lo más relevante de los debates e interrogantes suscitados por lo dicho por los anteriores autores lo resumía Alfredo Fierro, en las siguientes tesis ${ }^{13}$, que sintetizamos:

${ }^{13}$ FIERRO, A., "Psicología del aprendizaje para educadores. 20 tesis", Cuadernos de Pedagogía, $\mathrm{n}^{\circ} 135,1986$, pp. 45-51.

Educ. e Filos., Uberlândia, v. 20, n. 39, p. 89-130, jan./jun. 2006. 
1. Existen programaciones filogenéticas de los aprendizajes humanos y el hombre tiene limitaciones estructurales en relación con el volumen y otras características de lo que es capaz de aprender, por lo que todo potencial aprendiz es selectivo.

2. Llamamos aprendizaje a todo cambio en el potencial de conducta, como resultado de la práctica o de la experiencia.

3. El aprendizaje amplía el potencial y las posibilidades activas del ser humano.

4. La iniciación en el conocimiento científico es una variedad, compleja y superior, del proceso de aprendizaje, que está sujeta a las leyes de éste.

5. Existen numerosas modalidades de experiencias en las que puede consistir el aprendizaje. Algunas son puramente receptivas, observacionales, en general logradas por asociación; otras modalidades lo son de acción, prácticas, relacionadas con la motricidad y el ser activo del hombre, asociación entre estímulos y respuestas, combinación de percepción y acción.

6. El aprendizaje, sobre todo en sus niveles básicos, se produce de ordinario gracias a procesos activos en los que está comprometido algún hacer.

7. La ley del efecto o del resultado de la acción, que gobierna gran parte de los aprendizajes básicos, vale así mismo en niveles más altos de aprendizajes complejos y abstractos.

8. Todo aprendizaje es adapatativo y funcional para aprender a vivir en el medio; pero la adaptación no es sin más ajuste conformista al entorno, y puede servir para suscitar prácticas renovadoras.

9. El aprendizaje puede considerarse un proceso de reequilibración cognitiva, siendo la motivación (el interés, la necesidad, la curiosidad...) un elemento básico en el proceso de aprender.

10. No todo el aprendizaje se refleja en el momento de aprender; en este sentido, se puede hablar de aprendizajes latentes. 
11. El aprendizaje está relacionado con la capacidad de cada uno en un momento dado; presupone ciertas capacidades y produce la ampliación de las que se dispone. Desde el estado actual de su desarrollo cognitivo y conductual, existe una zona de potencial desarrollo inmediato donde se sitúan las mejores posibilidades de aprender, correspondiendo al educador su identificación y la promoción en ella de los aprendizajes.

12. Se puede hablar de cinco clases de capacidades o aprendizajes, que definirían otras tantas áreas de contenidos educativos: destrezas motrices, destrezas intelectuales, estrategias cognitivas, información verbal y actitudes.

13. Condición importante del aprendizaje es que sea significativo. En esta dirección, la programación consciente de estrategias de memoria, de solución de problemas, y de autorregulación amplían extraordinariamente la capacidad y eficacia del aprendizaje. Algunas programaciones cognoscitivas parecen constituir la clave de un aprendizaje inteligente, productivo y creador.

14. La conciencia no es precisa para que se produzca aprendizaje, pues también aprendemos inadvertidamente. Pero la conciencia explícita de la situación en la que aprendemos coopera a que lo hagamos.

Se aprende lo que se descubre por sí mismo, afirmaron, entre otros, Dewey, Freinet, Piaget y Bruner, mediante la solución de problemas cotidianos, aunque hay que señalar que siendo esto útil en el comienzo de la escolaridad, no todo ha de ser descubierto de nuevo por todos, y el propio conocimiento requiere tener informaciones previas. El aprendizaje se define mejor como proceso constructivo, siendo la perspectiva más conocida del constructivismo la que se fundamenta en la visión que subyace a la teoría de Piaget sobre el desarrollo intelectual, visión ésta que se tiende a completar con el pensamiento de Vigotsky sobre el lenguaje y la interacción social. En relación con esta visión y la del

Educ. e Filos., Uberlândia, v. 20, n. 39, p. 89-130, jan./jun. 2006. 
procesamiento de la información, interesa destacar por último, la importancia de la teoría del aprendizaje significativo (Ausubel, 1976), que elimina el ingenuismo del aprendizaje por descubrimiento y concede gran importancia al análisis de las ideas previas, a la organización previa de la información, y a la significatividad y potencialidad estructuradora de los contenidos formativos, para lo cual cobran relevancia los "organizadores previos".

Si en la perspectiva conductista interesa sobre todo la graduación "racional" adecuada de los contenidos de aprendizaje según su dificultad, en cambio, en la perspectiva piagetiana y constructiva, el profesor debe partir del estado del conocimiento de cada alumno - protagonista del proceso de aprendizaje - para graduar en cada caso el tipo de ayuda necesaria para avanzar en la construcción del conocimiento, sabiendo que el proceso de aprendizaje no es lineal y acumulativo, sino por aproximaciones simultáneas al objeto de conocimiento, lo que supone la realización de reorganizaciones cognitivas que resignifican, de modo retroactivo, las primeras interpretaciones dadas a los contenidos aprendidos.

De todos modos, aún debemos ser conscientes a la hora de terminar esta revisión de que el constructivismo nada dice sobre las condiciones externas de los sujetos que aprenden. En el aprendizaje intervienen otras variables que es necesario considerar para no caer en la psicologización de la acción escolar. No se debe olvidar que las escuelas y sistemas políticos de educación, por ejemplo, legitiman determinadas formas de conocimiento y perspectivas culturales que configuran los currículos escolares.

\subsection{El conocimiento como construcción social y la Pedagogía Crítica}

Esta cuestión, presente en el pensamiento y en la tradición anarquista y socialista, recibió un detenido análisis crítico de la mano de la Sociología de la Educación que a lo largo de los años sesenta y setenta se realizó desde la óptica del estructuralismo 
marxista, y bajo alguna influencia del pensamiento y de algunos de los conceptos de Gramsci. Éste mismo, Bourdieu con la teoría de la reproducción, Bernstein con sus conceptualizaciones sobre el poder y la elaboración de los discursos y de los dispositivos pedagógicos, Bowles y Gintis con su teoría de la correspondencia y Foucault con su tramada teorización, entre otros, venían a poner de relieve que el conocimiento es una construcción social, abriendo un modelo de pensar crítico que iba a ser profundizado y enriquecido por lo que se ha convenido en llamar la "nueva sociología de la educación", en la que confluirían diversas perspectivas teóricas. Frente a las teorizaciones sociológicas estructuralistas y deterministas se abría paso un análisis sociológico más matizado.

Mohamed Cherkaoui (Les paradoxes de la réussite scolaire, 1979) abría un interrogante sobre el determinismo sociológico y lo mismo harían más tarde Jacques Lautrey (Classes sociales, milieu familial, intelligence, 1980), Bernard Charlot (École et savoir dans les banlieues... et ailleurs, 1993), y Ph. Perrenoud (La construcción del éxito y del fracaso escolar), poniendo de relieve la existencia de excepciones sociológicas, luego de observar diferencias de desarrollo interindividuales, que aludían al principio de contradicción entre las lógicas escolares y las del mercado, a las que ya nos referimos.

Esto obligó a pensar con mas atención en los currículos escolares y en su determinación política, a lo que Mannheim había aludido en 1961, pasando a considerar los valores hegemónicos que representan y el papel de la educación como instrumento de distribución del conocimiento. En similar perspectiva de revisión se situába la Sociología del Curriculum, inaugurada desde Londres por Michel Young en 1971: el currículum escolar es analizado como uno de los mecanismos de distribución social del conocimiento, que se hace desde intereses y posiciones de clase y de poder, según las funciones asignadas a los aparatos escolares, lo que abocaría a un debate sobre el control ideológico. Frente a posiciones normativistas y positivas de "racionalidad técnica", este punto de vista interpretativo y socio-crítico obligaría a abordar, entonces, problemáticamente (por qué, cómo, qué, de qué modo enseñamos) los contenidos y las prácticas que tienen lugar en las escuelas.

Educ. e Filos., Uberlândia, v. 20, n. 39, p. 89-130, jan./jun. 2006. 
De este modo, desde el anterior enfoque sociológico macroestructural, preocupado por la estratificación social, la movilidad social y la división de clases, se pasaría a un enfoque más atento a las relaciones microsociales y contextualizadas, concediendo mayor importancia a la construcción del conocimiento escolar, a los procesos de escolarización, a las posibilidades de acceso al capital cultural, a la reproducción y al currículum (formal, explícito, real y oculto) con una visión global más compleja, "menos escolar" (eficacia, eficiencia... ) y más sociohistórica y política, abriéndose paso una "nueva sociología de la educación".

Este camino había sido también, en alguna medida, transitado por las reflexiones sobre la "desescolarización", la colonización cultural y el imperialismo cultural (M. Carnoy), y la "pedagogía liberadora" de P. Freire, como pauta de otras reflexiones referidas a los procesos de concienciación con un horizonte de transformación social, entendiendo en este caso el conocimiento como una construcción participada y crítica de los significados que se atribuyen a una realidad dada.

A esta visión interpretativa sobre el acceso y la distribución del conocimiento se llegó, sobre todo, con la ayuda de la reflexión suscitada alrededor de la llamada Escuela de Frankfurt y de su epígono Jürgen Habermas, con su formulación de la Teoría Crítica (M. Horkheimer sugirió este concepto en 1937). Frente a lo que llamaron "teoría tradicional", esto es, un conocimiento parcial y escindido de la realidad, sería posible construir una teoría crítica, esto es, una visión completa y valorativa de la realidad, elaborada desde la razón crítica; desde una racionalidad de naturaleza comunicativa, y aspirando a lograr un conocimiento emancipatorio, superior al conocimiento técnico y al conocimiento práctico.

Frente a la separación entre el mundo humano y el científico y frente a la especialización, postulados por la "teoría tradicional" (Popper, Wittgenstein, Círculo de Viena,...) que reduce la reflexión científica al examen de la metodología lógica y matemática, olvidando la actividad crítico-dialéctica, la teoría crítica pretende integrar la teoría y la praxis de los seres humanos, como dimensiones 
inseparables, y en lugar de limitarse a comprender y a explicar las distintas situaciones o aspectos de la cultura tal y como aparecen, considera a las personas como sujetos de la propia historia y miembros de la sociedad en la que se integran, y tiende a poner de relieve la dimensión activa y el carácter universal de la razón crítica, como razón reconstructiva, que persigue ideales racionales y aspira a lograr la emancipación de los seres humanos, liberándolos de la opresión existente en las sociedades actuales.

Desde estos antecedentes, según Habermas, las escuelas como "comunidades críticas de aprendizajes" debieran ser el lugar privilegiado de diálogo, de expresión democrática y de participación de los jóvenes en la construcción del conocimiento, de la autonomía y de la libertad. La pedagogía debiera ser, en este sentido, una teoría social crítica de la competencia comunicativa al servicio de la creación de una sociedad emancipatoria. Algo que exigiría afirmar una nueva consciencia epistemológica hecha de dialéctica entre conocimiento e interés, entre teoría y práctica, y llevar a cabo una transformación de las prácticas educativas. Por esto, los profesionales de la educación deberían poseer una teoría previa configuradora de su actividad y de sus decisiones, y una capacidad reflexiva sobre las prácticas cotidianas, con la finalidad de de-construir los hábitos pedagógicos enraizados y de poder contribuir a la educación con una teoría correctamente fundada.

Con algunas de estas y anteriores consideraciones se fueron constituyendo tanto la nueva Sociología de la Educación y del Currículum, como la Pedagogía Crítica. A partir del reader de Michel Young Knowledge and Control: New directions for the sociology of Education (1971) se abría paso desde el campo de las Ciencias de la Educación la nueva sociología del conocimiento, que analizaba los mecanismos lingüísticos al servicio de la reproducción, concentrándose, desde la metodología etnográfica, en los microniveles de la enseñanza. Camino este que seguiría en 1977 P. Willis con su estudio Learning to labour considerado un excepcional estudio de etnografía educativa, lo que no obsta para alertar sobre algunas de sus limitaciones, como señaló M. Sarip.

Educ. e Filos., Uberlândia, v. 20, n. 39, p. 89-130, jan./jun. 2006. 
Siguiendo un enfoque neo-marxista, distinto al anterior fenomenológico e interpretativo, otros autores como M. W. Apple o H. A. Giroux buscaron, en los años 80 y 90, en cambio, analizar la naturaleza ideológica de los procesos de instrucción escolar, ofreciendo luz - a través de la conexión entre lo macro-social y los microanálisis- sobre como la reproducción social está vinculada a las relaciones de aula, viendo la escuela no como un espacio para la "neutra" transmisión cultural sino como un posible arma de resistencia, una esfera contrahegemónica contra la alineación.

En 1979 Apple da a conocer su Ideología y Currículum, obra en la que recurriendo a Gramsci propone una visión de la ideología más compleja que la determinista de reflejo de la alienación y de la dominación; recurre también para ello a los estudios culturales del historiador inglés R. Williams, a la teoría de la reproducción de P. Bourdieu, a los sociólogos británicos del currículum, y a la tradición etnográfica, con cuyos análisis Apple se puede mover entre el estudio del currículum formal ("conocimiento legitimado") y el del currículum informal y oculto (teorizado por J. Anyon), para una mejor observación de la enseñanza ideológica. Bajo la influencia de Gramsci, de Freire y de la Escuela de Frankfurt, mantiene que la reproducción escolar no es, sin embargo, una fatalidad, en tanto que es posible abrir un espacio en las instituciones escolares para la acción humana, contradictorio con el poder, una reflexión que desarrollará en Educación y poder.

Al considerar las escuelas como espacios culturales con "autonomía relativa" construye H. A. Giroux sus reflexiones: las escuelas pueden ser lugares de posibilidades transformadoras, en los que se practique una pedagogía crítica, esto es, una política cultural contrahegemónica. Se trataría de ver las escuelas como comunidades críticas de aprendizaje social y cultural en interrelación con otros movimientos, redes y espacios sociales favorables a la transformación social, en torno a todos aquellos problemas y cuestiones que pudieran inpedir la democracia social. Una democracia social que debería ser promovida desde la transdisciplinariedad, la multiculturalidad y la construcción de un 
pensamiento complejo, al que Edgar Morin se ha referido lúcidamente.

\subsection{Concepciones y prácticas curriculares}

La conceptualización del término currículo es compleja. Se refiere, en todo caso, a fundamentales variables organizativas y académicas que interactúan entre sí, con la finalidad de que un determinado proceso de enseñanza-aprendizaje pueda tener lugar y, dada la naturaleza socio-histórica y cultural de los sistemas educativos, nada tiene de extraño que se hayan dado históricamente y hasta la actualidad distintas visiones de cuáles son esas variables fundamentales, cómo se articulan estructuralmente y cuál es y cómo ocurre su funcionalidad. Podríamos hablar así de un calidoscopio socio-histórico y técnico en el que confluyen tradiciones y variables de signo muy diverso, en relación con: las diversas teorías de la instrucción (que intentan proporcionar criterios de racionalidad para seleccionar y organizar el conocimiento escolar), las teorías de aprendizaje, las teorías organizativas de las instituciones escolares, las teorías sobre los docentes y sus funciones, y las teorías culturales y sociales.

De aquí que podríamos hablar del currículum como:

- tradición acumulativa del conocimiento organizado,

- conjunto de experiencias de aprendizaje,

- tecnología, o serie estructurada de objetivos de aprendizaje,

- plan de instrucción, o

- resolución de problemas

Es habitual en la actualidad aludir a tres grandes tendencias en cuanto al diseño y desarrollo curricular: el currículum como ingeniería, asentada sobre un ejercicio de racionalidad técnica; el currículum como proceso; y el currículum como constructo sociohistórico y enfoque crítico, sobre la base de la racionalidad práctica.

El currículum como ingeniería, inicialmente diseñado por Tyler en 1949, bajo influencia conductista y siguiendo a Clark L. Hull, como un proceso técnico planificado, desde una lógica positivista, pretendía trazar un percurso que permitiese alcanzar con garantías

Educ. e Filos., Uberlândia, v. 20, n. 39, p. 89-130, jan./jun. 2006. 
de éxito y eficacia lo prescrito en el sector de la educación básica, con superación del currículum disciplinario tradicional. Suponía llevar a la práctica un proceso de innovación de arriba-abajo, enlazando con la tecnología de la enseñanza skinneriana. En este caso, se distinguía netamente entre diseño y desarrollo, entre expertos que legitiman las prescripciones y el profesorado que aplica las pautas esperadas, partiendo de la noción de currículo como problema técnico, siendo desarrollado posteriormente por autores como Taba y Johnson.

Este modelo de "racionalidad técnica" ha alcanzado un importante predicamento, dado que el modo de toma de decisiones se adecua a la lógica organizativa en los sistemas y organizaciones centralizadas y se revela con notable operatividad a la hora de la gestión de recursos, aunque, sin embargo, favorece la existencia de conductas burocráticas y pasivizantes entre el profesorado.

En el marco de las investigaciones y debates anglo-americanos sobre el currículo, a raíz de un trabajo de J. J. Schwab (1969) se abrió una nueva perspectiva al procurar implicar a los profesores en la definición curricular: esto llevó a pensar en los procesos de interacción y de regulación de la actividad docente, a partir del propio punto de vista situacional y contextual de los implicados, lo que a su vez condujo a la investigación de la acción y al planteamiento del desarrollo curricular a través de situaciones de cooperación entre los docentes.

Este punto de vista parte de la tesis de que el desarrollo curricular es una práctica social, y que por ello no se infiere necesariamente de las proposiciones de una autoridad externa y superior, si previamente estas proposiciones no fuesen aceptadas y asumidas desde los propios esquemas conceptuales y profesionales de los docentes, a los que, así, se les reconoce un protagonismo profesional, que lleva a implicarlos en la elaboración del currículo, apostándose entonces por principios de procedimiento, frente al modelo de objetivos propios de la racionalidad técnica y burocrática.

En esta perspectiva, los modelos de solución de problemas, que han elaborado Lawrence Stenhouse y John Elliot en Inglaterra, 
o los modelos de planificación constructivistas orientados al aula, que suponen procesos colaborativos de diseño, favorecen las innovaciones curriculares, al hacer hincapié en las experiencias y en la creación de oportunidades de aprendizaje durante la fase de desarrollo curricular, suponiendo todo una cierta imagen del "profesor como investigador". El currículum sería un proyecto o hipótesis de trabajo sobre el conjunto de experiencias educativas a desarrollar en un determinado contexto organizativo y de aprendizaje.

Gran impulsor de este modelo fue L. Stenhouse, quien desde 1970 fue director del "Centre for Applied Research in Education" de la Universidad de East Anglia, siendo autor de la fundamental An Introduction to Currículum Research and Development (1975) en donde explicita este modelo de proceso para el desarrollo curricular, mostrándolo a través del Humanities Currículum Project. Esta perspectiva condujo la reflexión curricular al mismo corazón de los centros escolares como unidades de programación, haciendo de ellas los centros de cambio, tal como, entre otros, señaló Barry MacDonall: "La escuela es la unidad ideal para la investigación y el desarrollo del currículum".

Una última tendencia en cuanto al currículum es la denominada de "reconceptualización del currículum", encaminada hacia la construcción del llamado "currículum crítico", que asume lo que supone el "modelo de procesos" en cuanto al protagonismo docente en el propio diseño curricular, al tiempo que manifiesta una fuerte predilección por introducir curricularmente las cuestiones sociales problemáticas, desde la experiencia biográfica social y cultural diferente de los escolares, dando lugar a una sociología del currículum muy ligada a la sociología del conocimiento.

Podríamos terminar esta presentación de las tendencias en cuanto a los estudios y propuestas currículares señalando que el currículum como práctica social es borroso, por su carácter dinámico, complejo y un punto impredecible. Por eso, quizás, su comprensión pueda necesitar de las tres grandes corrientes explicativas. Se necesita la intervención de las Administraciones

Educ. e Filos., Uberlândia, v. 20, n. 39, p. 89-130, jan./jun. 2006. 
públicas, pues es precisa una oferta curricular global, racional y común, pero al mismo tiempo, su diseño y desarrollo debe obedecer a una responsabilidad compartida social y profesionalmente; hay que planificarlo con criterios de racionalidad técnica, aplicando el conocimiento experto del que se dispone y se construye, porque su naturaleza es precisamente la intencionalidad, pero también deben intervenir los mecanismos de deliberación colaborativa.

\subsection{Teoría y práctica docente}

Existe una crisis de identidad en el rol social y una falta de claridad en cuanto a perfil, competencias, y destrezas deseables en los profesores de niveles educativos de carácter no universitario, a pesar de tener una competencia social oficialmente establecida, lo que incide en los modelos y supuestos de su formación. Una amplia literatura sociológica y didáctica se viene extendiendo sobre ello, y quizás, para comenzar, lo más acertado sea reconocer que el colectivo profesional docente es sumamente heterogéneo, dispar y con jerarquización interna, lo que conlleva una diversidad de culturas y de estilos de trabajo suficiente como para ser cuidadosos en la posible generalización de sus rasgos caracterizadores, más aún en un entorno cambiante en cuanto a las demandas sociales y a los retos educativos. Así, la pregunta acerca de cómo deberían ser los profesores capaces de responder a ello, encierra preguntas de fundamental importancia sobre la escuela y sus funciones y sobre el currículum y la didáctica, para desde las respuestas que se den poder aquilatar y re-definir los saberes profesionales docentes, es decir, el cuerpo de conocimiento sistemático y especializado propio, que incluirá el dominio de unos conceptos y de un lenguaje técnico específico (como su fuente de legitimidad social) y determinadas competencias, destrezas y capacidades prácticas para desarrollar conscientemente su desempeño profesional.

Por unas y otras razones la profesión docente se ha convertido desde los pasados años setenta en un nuevo objeto de investigación educativa, a tal punto que la Pedagogía se ha convertido en gran medida en un discurso sobre el profesorado, como escribió José 
Contreras ${ }^{14}$. Y así también lo ha visto Ángel Pérez, al decir:

"En los últimos años, la preocupación por el desarrollo profesional del docente, tanto en sus aspectos de formación, como de ejercicio de su práctica, condiciones de trabajo, consideración social, control y evaluación..., se ha convertido no sólo en un problema político, administrativo y técnico, sino en un importante objeto de estudio teórico, investigación, debate público y desarrollo legislativo (Carnegie Task Force on Teaching, 1986; Homes Group, 1986). En la mayoría de los estudios teóricos y en las propuestas o proyectos de reforma (LOGSE incluida), la necesaria transformación de la escuela y el incremento de calidad de la enseñanza se vincula habitualmente con la modificación de la función docente y el necesario enriquecimiento del desarrollo profesional de los enseñantes" ${ }^{15}$.

Esta cuestión, muy visible en las investigaciones llevadas a cabo ya desde hace varias décadas en los EEUU y en el RU, ha terminado incorporándose a la agenda de preocupaciones de muchos otros países. La búsqueda, así, del "profesor eficaz" se tradujo en sistemas de formación muy preocupados con la ejecución de comportamientos docentes predeterminados, siguiendo los criterios propios de la racionalidad técnica funcionalista, con su exponente en los programas formativos de micro-enseñanza para el logro de competencias técnicas específicas y el adiestramiento en las distintas especificaciones de la actuación docente, pero en los años ochenta las orientaciones iban a cambiar.

${ }^{14}$ CONTRERAS, DOMINGO, J., “Teoría y práctica docente”, Cuadernos de Pedagogía, $n^{o}$ 253, 1996, p. 92. De este autor es también el importante ensayo La autonomía del profesorado (Morata, Madrid, 1997), donde se abordan todas las cuestiones clave sobre lo que significa hoy la profesionalidad docente.

${ }^{15}$ PÉREZ GÓMEZ, A., "Autonomía profesional y control democrático", Cuadernos de Pedagogía, $\mathrm{n}^{\circ}$ 220, 1993, p. 25.

Educ. e Filos., Uberlândia, v. 20, n. 39, p. 89-130, jan./jun. 2006. 
Ahora, la crisis observada en los modelos de innovación didáctica de arriba-abajo, por su falta de eficacia, los cambios de perspectiva en la comprensión del profesorado y la presencia del cognitivismo con sus referencias al pensamiento de los profesores como factor importante para entender su práctica docente real, condujeron a la consideración de los profesores como agentes activos y creadores de pensamiento y prácticas y no sólo como "reproductores" del pensamiento experto. Se formularía también la figura de los docentes como investigadores sobre su práctica, y en este sentido se comenzarían a tomar en cuenta las experiencias de desarrollo curricular basadas en el propio profesorado, es decir, los docentes como protagonistas, como alternativa a la concepción tecnológica del currículum. Investigadores como Zeichner (1985), Stenhouse (1984), Elliot o Schön impulsaron decisivamente esta orientación abierta por Schwab en 1969 con su enfoque prácticodeliberativo del currículum, asunto éste al que ya nos hemos referido.

La revisión crítica de la misión de los centros escolares, la toma en consideración de la cultura organizativa y de la cultura de la enseñanza en la que se socializan los profesores, abría las puertas a un modelo de profesionalización crítico-reflexivo, contrapuesto a los modelos burocrático, práctico-artesanal y al técnico.

En este sentido, tal revisión es una de las claves fundamentales de la distinta percepción del oficio docente. Si le atribuimos a las escuelas un valor de mediación que facilite a las nuevas generaciones el desarrollo autónomo de su capacidad de reflexión y de actuación, de reconstrucción y transformación de la cultura y del conocimiento experiencial, fruto de los procesos de socialización con los que cada alumno llega a la escuela, necesariamente cambia la cultura y la impostura docente, ya que se requiere de ellos mayor autonomía profesional e independencia intelectual.

Se han llegado a categorizar hasta cuatro modelos o enfoques para definir y categorizar la profesión docente, y en ellos nos detendremos un momento. Por una parte, el modelo prácticoartesanal, que concibe la enseñanza como una actividad artesanal. El conocimiento sobre la misma se habría ido acumulando a lo 
largo del tiempo, por procesos de ensayo y error, dando lugar a una sabiduría profesional, que se transmite entre generaciones de profesores, mediante el contacto con maestros experimentados, y se aprende en un largo proceso de inducción y socialización profesional del aprendiz hasta lograr el dominio empírico de reglas prácticas y de los procedimientos técnicos del oficio. Se trata de un modelo, analizado por una considerable literatura científica, que goza de notable influencia en el pensar común de la sociedad, así como en el pensar y hacer del propio profesorado. Aquí, el conocimiento experto se genera en los intercambios entre el profesional experimentado y el aprendiz, bajo la presión de la tradición histórica, de las inercias institucionales y de los hábitos adquiridos y reproducidos por los docentes, alumnos y la comunidad local. El futuro docente se socializa, de este modo, dentro de la institución, aceptando la cultura profesional heredada y los roles profesionales correspondientes, como han escrito $\mathrm{M}$. Fullan y A. Hargreaves en 1992.

Estaría, por otra parte, el modelo burocrático tradicional, sometido a una normatividad académica y organizativa, que hunde sus raíces en la cultura conservadora estatal de raíces positivistas decimonónicas; un modelo que encuentra su gran amparo intelectual en tesis expresadas por los sociólogos Durkheim y Weber.

Hay que hablar, también, de un enfoque técnico-academicista o tecnocrático. En este modelo el conocimiento experto se desarrolla como una derivación más o menos directa o lejana del conocimiento científico elaborado por especialistas externos y se procura aplicar siguiendo prescripciones técnicas por parte de los docentes, los prácticos, armados con las competencias comportamentales requeridas para la ejecución correcta de lo diseñado por los "técnicos", según una mentalidad tecnocrática y eficientista. Un modelo proceso-producto que guarda íntimas conexiones con modelos de aprendizaje y de instrucción conductistas.

Un modelo que, como indicó Pérez Gómez, "ignora la singularidad epistemológica de los fenómenos y procesos sociales, así como el carácter ético, político, inacabado y contingente de las

Educ. e Filos., Uberlândia, v. 20, n. 39, p. 89-130, jan./jun. 2006. 
formaciones humanas"16; un modelo que hace perder a los profesores su capacidad de autonomía profesional, al deber subordinarse al "conocimiento experto" ("un régimen de verdad", en expresión foucaultiana). Las consecuencias del sometimiento a esta racionalidad instrumental, que han ocupado la atención intelectual de Apple $^{17}$, de Giroux, o de Popkewitz ${ }^{18}$, se traducen en la desprofesionalización y descualificación o en la posible pérdida de capacidades profesionales, con referencia al no dominio de capacidades profesionales deseables.

Pero la enseñanza no se reduce ni a la transmisión mecánica de contenidos académicos ni a la aplicación lineal de supuestas técnicas eficaces y generalizables. Al contrario, hay que tener en cuenta la mayor complejidad de todo lo que significa la educación y el alcance del pensamiento de los profesores, que en parte orienta y dirige su práctica profesional, debiéndose hablar a este respecto de un pensamiento que se organiza en torno a esquemas de conocimiento (que suelen representarse en el lenguaje y en la mente de los profesores a través de imágenes, metáforas y principios prácticos), constantemente reconstruidos a través de la experiencia profesional. Al aludir al pensamiento del profesor nos referimos a un conjunto de variables significativas sobre el sistema escolar y el didáctico (planificación de aula, toma de decisiones, autorreflexión, profesional, creencias y teorías implícitas...), que, junto con otras, mediatizan, condicionan e influyen en aspectos centrales del desarrollo de la enseñanza. Estaríamos, pues, ante un cuarto modelo, en este caso sistémico-ecológico.

De aquí que Shön y Zeichner hayan definido la figura del "profesor reflexivo", en el que se produce una interconexión teoría-

${ }^{16}$ PÉREZ GÓMEZ, A., "Autonomía profesional y control democrático", op. cit., 26.

17 APPLE, M., Ideología y currículum, Akal, Madrid, 1986; y Maestros y textos. Una economía política de las relaciones de clase y de sexo en la ecuación, Paidós/MEC, Barcelona, 1989.

${ }^{18}$ POPKEWITZ, Th., Formación del profesorado. Tradición, teoría, práctica, Universidad de Valencia, Valencia, 1990.

Educ. e Filos., Uberlândia, v. 20, n. 39, p. 89-130, jan./jun. 2006. 
práctica, y para el que se contempla la teoría como la producción de formas de discurso que surgen del examen y análisis de las situaciones contextuales, en un clima colaborativo, para que se facilite la necesaria discusión y tomas de acuerdo en común.

En este caso, los saberes de los profesores no se limitan a contenidos bien delimitados; abarcan, por el contrario, una gran diversidad de objetos, de cuestiones y de problemas, todos relacionados con su trabajo. Es decir, "los saberes profesionales de los profesores parecen ser, por tanto, compuestos, plurales, y heterogéneos, manifestación que son de un saber ser y de un saber hacer bastante diversificados, provenientes de fuentes variadas y posiblemente también de naturaleza diferente", según revela una importante literatura científica al respecto. Se inscriben, por otra parte, en una destacadísima dimensión temporal, es decir, en una historia de vida de cada profesor y se construyen a lo largo de una carrera. Todo comienza, además, en su propia trayectoria preprofesional, como ponen de relieve, las diversas y valiosas investigaciones realizadas a lo largo de las dos últimas décadas ${ }^{19}$.

De todo lo expuesto y como conclusión de las investigaciones ${ }^{20}$ surge como constatación general que los saberes que sirven de base para la enseñanza, o, dicho de otro modo, los fundamentos del saber-enseñar no se reducen a un "sistema cognitivo" que, como un computador, procesa las informaciones a partir de un programa anteriormente definido e independiente, tanto del contexto de acción del que forma parte, cuanto de la historia anterior que lo precede. La cognición del profesor parece ser mucho más interpretativa y lingüística, que ligada a un sistema cognitivo de

${ }^{19}$ NÓVOA, A., Vidas de professores, Porto Ed., Porto, 1992; GOODSON, I., Historias de vida del profesorado, Octaedro, Barcelona, 2004.

${ }^{20}$ Entre otros, PAQUAY, L., ALTET, M., CHARLIER, E. y PERRENOUD, O., Former des enseignants. Quelles stratégies? Quelles compétences?, De Boeck, Bruxelas, 1996; y RAYMOND, D., BUTT, R. L. y YAMAGISHI, R., “Savoirs pré-professionnels et formation fondamentale: approche autobiographique". In: GAUTHIER, C.; MELLOUKI, M. e TARDIF, M. (dirs.), Le savoir des enseignants: unité et diversité, Logiques, Montreal, 1993, pp. 137-168.

Educ. e Filos., Uberlândia, v. 20, n. 39, p. 89-130, jan./jun. 2006. 
procesamiento de la información. Es más un proceso discursivo y narrativo enraizado en la historia de vida pre-profesional y profesional del individuo, una historia que es portadora de sentido, de lenguaje y de significados.

Por todo lo dicho, hay que concluir que los fundamentos de la enseñanza son, al mismo tiempo, existenciales, sociales y pragmáticos ${ }^{21}$.

Ante todo este conjunto de reflexiones y evidencias se habla también de un enfoque hermenéutico-reflexivo y crítico en cuanto al oficio docente, partiendo del supuesto de que "la enseñanza es una actividad compleja, que se desarrolla en escenarios singulares, claramente determinada por el contexto, con resultados siempre en gran parte imprevisibles y cargada de conflictos de valor que requieren opciones éticas y políticas", tal como certeramente ha señalado Pérez Gómez.

Por todo esto, el conocimiento profesional emerge en buena medida en y desde la práctica y se legitima en proyectos de experimentación reflexiva y compartida en el propio proceso de construcción y de reconstrucción de la práctica educativa. Se trata de un conocimiento reflexivo y situacional, utilizando, sin duda, el conocimiento previo disponible.

Profundizando esta propuesta de modelo cognoscitivo hermenéutico se sitúa el enfoque crítico. Carr y Kemmis ${ }^{22}$, en este sentido último, pusieron de relieve que podría no ser suficiente una teoría educativa sobre la profesión docente fundamentada en las interpretaciones de los profesores ("el profesor reflexivo"), ya que este autoentendimiento podría estar ideológicamente deformado por las condiciones de la existencia docente, por lo que instan a la superación intelectual crítica de las posibles limitaciones situacionales condicionantes, desde el horizonte de la democracia y de la ética deliberativa, siendo conscientes de las consideraciones

${ }^{21}$ TARDIF, M., RAYMOND, D., "Saberes, tempo e aprendizagem do trabalho no magisterio", Educaçao e Sociedade (CEDES, Campinas) n 73, 2000, p. 213.

${ }^{22}$ CARR, W., KEMMIS, S., Teoría crítica de la enseñanza. La investigación-acción en la formación del profesorado, Martínez Roca, Barcelona, 1988. 
normativas (valorativas), que se derivan de su compromiso con la justicia social.

Estos antecedentes llevaron a revisar las concepciones y prácticas curriculares, así como los modelos de acción docente. Frente a las concepciones asentadas sobre los criterios propios de la racionalidad técnica se abrieron paso, pues, las concepciones del currículum como proceso y conjunto de experiencias de aprendizaje, en concordancia con el constructivismo psicológico, y también la visión de los docentes como investigadores y como protagonistas de la elaboración curricular. Fueron surgiendo igualmente, la perspectiva del aprendizaje social compartido que resalta sus dimensiones socio-políticas, y la imagen de los profesores como creadores de pensamiento y de prácticas sociales emancipatorias y democráticas, lo que tuvo como consecuencia así mismo una fuerte modificación de la cultura y de la organización de los centros escolares.

$* * * * * * * *$

Este podría ser el dibujo de lo más notable del nuevo panorama de los saberes de la educación: no es facil su trazado. Sin duda, hay también otras posibles lecturas.

Data de Registro 26/04/06

Data de Aceite 15/05/06

Educ. e Filos., Uberlândia, v. 20, n. 39, p. 89-130, jan./jun. 2006. 